\title{
The Livelihood and Cultural Change of the Highland Miao People in Yunnan
}

\author{
Zheng Yu \\ Yunnan University \\ Zhang Mengyao \\ Yunnan University
}

Culture is the core expression and reflection of ethnicity. As a south-east Asian ethnic group, the ethnicity of the Yunnan Miao most notably appears in their highland migration culture. However, their highland migration culture is the result of their shifting cultivation livelihoods rather than state effect, and was widely penetrated in their language, architecture, clothing, ceremony and religious perception. Shifting cultivation, including slash-and-burn cultivation, gathering and hunting, and exchanges with surrounding ethnic groups, together shaped the features of mobility, limits and mutual benefits of highland migration culture of Miao people in Yunnan. Nowadays, the highland migration culture is constantly changing.

Keywords: Miao people, livelihood, highland migration culture, ethnicity

\section{INTRODUCTION}

According to the census of 2000 China national population data, there are about 8.94 million Miao people around China, including 1.04 million in Yunnan province. The Miao people in Yunnan province and Southeast Asian countries generally live in the alpine forest areas 1000 meters above the sea level, with an average annual temperature of $15^{\circ} \mathrm{C}$ to $20^{\circ} \mathrm{C}$, where there is a subtropical climate. "Miao" seems to be a term imposed by the Chinese according to Frank M. LeBar et al $(1964,64)$. LeBar et al also state that Chinese identify particular Miao groups by cultural features, such as "dress, hair style, occupation, etc." (ibid.) Based on those cultural features rather than kinship system, Miao people were identified as different branches, such as Hmong and Ad Hmaob. And each branch can be further identified according to certain customs and habits. Moreover, their characteristics distinguish from Han people who usually migrate for seeking jobs, labor, and earning money (Wang and Beja 1999, 106-119).

The studies on Miao people of this region include "Hmong at the Turning Point in Laos" written by an American Hmong scholar Yang Dao (1993); "Migrants, Runaways and Opium Growers: Origins of the Hmong in Laos and Siam in the Nineteenth and Early Twentieth Centuries" by Christian Culas in "Turbulent Times and Enduring Peoples edited by Jean Michaud and Jan Ovensen (2000), and "Cultural Capital: Old Hmong Culture in Modern Times" by CziasarhNeng Yang (2002). Moreover, J. Lemoine's (1972) social organization analysis of Qing-Miao in Laos, William. R. Geddes's (1976) discussion on the economic and cultural role of opium among the Hmong of Thailiand, N. Tapp's (2008) study on the structural adaptation between refugees, religion and ethnic groups in China, GaryYia Lee's (1981) study on inheritance and protection of Miao traditional religious culture, and Vietnamese scholar Chen 
Youshan's (1996) study that systematically introduces the basic situation of the Hmong in Vietnam are also present.

Looking back to China, there are also some scholars who have done remarkable studies on Miao people, especially Shi Maoming's (2004) study on transnational Hmong, Yang Yudong's (2008) study on Miao people's migration, Zheng Yu and Zeng Jing's (2003) ethnographic study about the ceremony of Vietnam Miao, and the studies done by Gu Wenfeng, Xiong Yuyou (2010).

Relevant studies demonstrated and analyzed the inner meaning and influence of the Miao people from multiple dimensions of their society and culture, and actually implied that the social experience of migration and its derivatives is the core expression of the highland culture. However, if we agree with the view that ethnicity contains dual meanings of blood and culture (Fenton 2009), just as Steve Harrell (2001:16) says,

\section{Humans, living in one place and associating with a particular group of people, readily and universally classify humanity into selves and others, attributing to the others different ways of doing things, different ways of talking, different places where they ought to be, different relations of kinship and descent, and different looks.}

then we should realize that it is the core concept of culture and not biology that can explain and express ethnicity. And ethnicity usually refers to the cultural identity, which is the unique attribute of an ethnic group that distinguishes it from other ethnic groups, with particular emphasis on social and cultural differences (Sun 1998, 24 31), such as religion, food, language, acceptable social temperament, attire, folklore, ethnic origin common ancestry and social experience passed down from generation to generation (Eriksen 1993). In this regard, long-term migration as a kind of social experience endows the Miao people with significant characteristics of ethnicity. Furthermore, we can draw a conclusion that the highland migration culture is the major premise of the ethnicity of the Miao people.

Therefore, we can also apply Scott's main point that the highland migration culture is the result of the "state effect", or asymmetric power relationships with dominant lowland polities. Nevertheless, this inadequately explains the situations in Yunnan which Scott (2009) ascribes to Zomia, the Southeast Asian Mass if out of reach of politically dominant lowland populations. In addition, when Julian Steward's cultural ecology approach (Steward 1955/1985, 14) linked livelihoods with ethnic behavior and culture, which was the basis for Lin Yaohua's (1985,104-142) description of Chinese economic and cultural type, it is not so difficult to suggest that there is a close relationship between the economic structure of the Miao people with their livelihood, highland culture as well as their ethnicity. Thus, we argue in this article that it is principally the livelihood rather than the state's effects that influenced the ethnicity and the highland migration culture and features of Miao people in Yunnan.

\section{RESEARCH SITE AND METHODS}

In order to investigate the ethnicity, its performance of the highlanders of Yunnan Miao people and to find out the authentic and practical reasons, we conducted anthropological fieldwork in a selected number of Miao villages, including villages $\mathrm{S}$ and $\mathrm{B}$ in Dongcun Town, Fumin County, northeast of Kunming, Yunnan; villages C, Z, and Q in Jinchang Town, Maguan County, and village L, Qiaotou Township, Hekou County, Honghe Hani and Yi Autonomous Prefecture, the latter bordering on Vietnam. Involving the international migration of the Miao people, we have also investigated some Miao settlements in contiguous areas such as Hoang Lien Province, Vietnam. However, this paper mainly focuses on Miao in Yunnan.

Fieldwork accumulated for more than one year, adopting methods combining the etic and emic perspectives through participant observation and in-depth interviewing in these villages. We were able to eat, live and work with the villagers together in order to access a "thick description" (Geertz 1973, 3 30) to deeply and systematically understand the indigenous social structure and cultural model of the village. 
Our analysis process adopted a combination of inductive and deductive reasoning. We documented the basic characteristics of Yunnan Miao highland migration culture from multiple dimensions, such as language, architecture, attire, rituals and religion. On this basis, we believe these characteristics of the highland migration culture of Yunnan Miao people are shaped by their long-term shifting cultivation livelihoods, and consequently it provides evidence from multiple aspects to support our argument. Finally, we described and analyzed the changes in the modern society of the Yunnan Miao people's highland migration culture and its livelihood foundation from a longitudinal historical analytical method.

\section{RESEARCH FINDINGS}

The Traditional Kernel and Its Modern Continuation of Miao People's Highland Migration Culture

Miao traditional highland migration culture is reflected in all aspects of their social life, which encompasses people's concepts and practices regarding nature and resources, and involves their livelihood and behavior patterns, associated with supernatural cultural systems, literature and art, etc. A highland nomadism is the foundation of Yunnan Miao people's migration culture. As folk proverb says, once the peach trees bloom, the Miao people begin to move, and there is no land for the Miao people to settle down, as well as there is no stump for the old crow to live on, resulting that the Miao people have to carry the ploughshare to beg for foods; etc.

This kind of culture is gradually formed in the long historical process. From the establishment of the "Three Miao" kingdom by their ancestors, to the rise of Jingman, ${ }^{1}$ and then they moved to Wuling and Wuxi (Wu 2006, 110-112), ${ }^{2}$ and finally they scattered in the Yunnan-Guizhou plateau. Up to the present, the frequent migration of Miao people still occurs continuously. After the establishment of the People's Republic of China in 1949, the state has required all ethnic minorities (minzu) to settle in permanent communities. However, even during a strict administrative management period from the 1950s to early 1990s, Miao people continued to move on a large scale. Especially during the Great Leap Forward years from 1959 to 1961, Miao moved in response to the central influence of Chinese social and political movements.

In the meantime, there are sporadic cross-border Miao bride exchanges between China and Vietnam. Similarly, the Hmong have moved across domestic terrain based on kinship connections. For example, two stem families moved to village B near Kunming in the 1960s relying on affinity. Another case happened during the Sino-Vietnamese war in 1979. Because of Vietnam's anti-Chinese policy, a large number of frontier Miao people moved into China and then they became refugees because they were not distributed cultivable land. For example, eight nuclear families moved to Village $\mathrm{C}$ in Maguan County, China, on the Sino-Vietnamese border, and all were left landless as refugees.

From 1976 to 1999 , 32,121 Miao people moved spontaneously within Vietnam's Hoang Lien province. And even in the early 1990s, there were still about 3,000 people who moved into this region each year (Chen 1996). In contemporary China, this kind of movement still does not disappear. Instead, some nucleus family and stem family have completely left their home village and moved to some other places as the adults were available to make living, which is relatively rare among other ethnic minorities. Such as village $G$ on China-Laos border in Xishuangbanna, China, there were eight nucleus Miao families who used to live in Wenshan, Honghe and other places in Yunnan, China, relocated in G village for finding more barren mountains. Within them, two families that arrived earlier were officially resettled by the local government, and the other six chose to move to elsewhere. Another example is village B near Kunming, there were two families who also moved away B villages completely because of renting cultivated land from other villages to live. Yet it is worth noting that most of them never returned to the former residence after relocation. Therefore, the contemporary Miao people's movement is still a common phenomenon.

The long-term migration tradition has deeply affected the social and cultural traces on such groups, which is reflected in many aspects. The first and the most significant aspect is their livelihood. Miao people chronically practice slash-and-burn cultivation in shifting rotational fields. The second aspect is about their social life. Their social structure is highly diversified and the internal structure of different 
nations, regions and ethnic groups is totally complex and flexible. Although what we have seen on the surface is extremely scattered, it can integrate ethnic groups on a large scale through periodic ceremony and ethnicity identity. And even the CIA effectively mobilized hundreds of thousands of people to participate in American "secret war" in Laos in the 1960s. ${ }^{3}$ Hundreds of years' floating has made their culture extremely diverse. All in all, migratory element was profoundly embodied in their branches, language, village layout, literature, costumes, architecture, and ritual and religion, etc.

Firstly, among the three major Miao dialect regions, the languages spoken by the Miao people in Yunnan and Southeast Asia are the western dialects, which are divided into eight sub-dialects, and some of which differ by more than 30 percent. In addition, apart from language and clothing, this part of Miao has dozens of branches, including Hmongb Shib (or Hmongb Lens), Hmongb Nzhuab, Hmongb Dleub, Hmongb Shuat, Hmongb Bes, etc. (Xiong and Yang 2010). Hence, their festivals, rituals, and customs are systematically different. Some branches even strictly forbid intermarriage because of warfare between them.

Secondly, in terms of village settlement patterns, the boundaries between villages and even families' cultivated lands are mostly blurred, which is not only in terms of geographical space, but also in terms of social and cultural psychology. For example, almost all Miao villages in Yunnan have no fencing, and people's understanding of the village boundary is not precisely demarcated. Therefore, it caused the phenomenon of "mosaic parcel" in the village to some extent, which refers to the arrangement that the lands between families and villages are mixed and coexist. An extreme case is that some families' arable lands consist of small plots scattered across six or seven different locations. Additionally, in a cultural aspect, such as the ritual activity "dragon-worship" in the village, is traditionally presided over by each household in turn every year, rather than by someone or an organization appointing and arranging who presided over it, suggesting that the families among the village are homogeneous and equal. Moreover, the land-use patterns of the village also tend to be highly fragmented. Thus, this kind significant equality and fragmentation apparently have resulted from long-term floating.

Thirdly, in the aspects of culture, art and clothing, there are direct connections between them and the myths and legends that are related to the movement and war in this region. As we can see, clothing decorative pattern is regarded as the memory of migration routes; the unique wrapped hair style of Ad Hmaob is said to be used to store cropping seeds when moving in emergency; part of the traditional houses which are called chacha-house with shapes of $\mathrm{X}$ are extremely simple and easy that are made of stumps and thatches.

Fourthly, in ceremonial and religious aspects, such as the clan ritual "zuosuo" only occurs in Hmongb Nzhuab. Meanwhile, the processes and sequences of weddings and funerals and even other rituals are totally different between branches. Even among the clan within one Hmong branch, the specific links of many important rituals of each clan are extremely different. As a result, the pedigree of their gods was also transient. Such as ancestral sacrifice was mostly limited to three generations or less.

As we can see from above, migration is the kernel of the Miao people's highland culture and it has penetrated and reflected in all aspect of their culture. Therefore, it was with this recognition of British anthropologist and Miao specialist, the late Nicholas Tapp, who pointed out that the Miao people's ability to control the "border" is especially outstanding, and they are so "good at crossing border" (Tapp 2008, 23-31). However, relevant study has paid more attention to the cultural and artistic aspects of the migration culture of the Miao ethnic group. For this reason, we will focus more on the formation of this migration culture below.

\section{The Livelihood Basis and Distinctions of Miao People's Highland Migration Culture}

Until the end of the last century, the mainstream view in mainland China was that the Miao people's migration was forced by war. While Scott (2009) argued that the migration of the ethnic groups in Zomia, including Miao people in Yunnan province, were more likely to be an active choice to evade the central government of a state. Such factors may surely have influenced the Miao people's migration. However, we think the means of livelihood have been the core factor leading to this active choice as well. Our reading of Miao history tells that the most common reason of migration was due to the attraction of wider 
landscapes and vast forests for subsistence reasons. It must be emphasized that such livelihood pattern not only include the slash-and-burn cultivation, but also gathering and hunting, and exchange relationships with neighboring ethnic groups, which co-shaped the mobility, limits and mutual benefit of Miao people's livelihoods and the highland migration culture in Yunnan.

First of all, we shall discuss the mobility of traditional livelihoods. After moving into Yunnan, nomadic slash-and- burn cultivation was still the major livelihood of the Miao people (Yin 2008). Even if some people chose to rent land from other ethnic groups, such as County $\mathrm{K}$ in Yunnan, the barren mountains they exploited were still more than three times the area of rented cultivated land. Therefore, shifting livelihoods had always been their dominant mode of subsistence as a whole. The Miao people tend to live in the mountains that are steep with poor soils and vast barren mountainsides that are 1,000 meters above sea level. The crops they planted mainly included upland rice, corn, buckwheat, sorghum, potatoes, beans, etc., and the main cash crops were hemp, indigo, tobacco, and peanuts. After fully accounting for the local seasonal changes, they used the distinct characteristics of the winter and spring dry season to cut down trees, burn the ash for fertilizer, and then wait for the rainy season in April and May after the seeds are placed in the soil to germinate and grow. Finally, they harvest all kinds of crops in autumn.

Therefore, forest available for logging and burning are required for this livelihood so that the vast mountain and forest resources distributed along the border at Yunnan border area and neighboring countries of Vietnam, Laos, Thailand, and Myanmar attracted so many Miao people to move into these places. Nevertheless, whenever the fertility of mountain soils is exhausted, they have to seek for new lands and forests so as to continue the migration (Cang 2004, 111). Consequently, they were called "the farmers in the forest" (Golden 2012, 82-83), accompanied with creating a lot of distinctive field tools, techniques, methods and organizations. A suitable case of cultivation equipment is that the Miao people's plough bar is very thick but rigid and flexible, so it is helpful to cultivate the mountain and forest barren land with higher efficiency. They also invented some methods to prevent mountain landslides, transform slopes into terraces, and extend the life of cultivated land. And in the process of production and organization, they mostly use relatives' cooperation and collective work to cultivate.

However, due to the low yield of slash-and-burn cultivation, they still rely on hunting and gathering as an important food supplement. Hence, when big animals are found, they would chase them so the hunted meat not only satisfies hunger, but also the fur can be used to make clothes to keep warm, and as commodities to trade with other ethnic groups. They have hundreds of flora sources for gathering. Although the yield is not so high, they are constantly changing their comestibles and ways of procuring, thus protecting the fragile ecological environment in karst mountain areas where they live (Yang 2007, 24-33).

Secondly, the traditional livelihood of Miao people is embodied in an indigenous understanding of the limits of natural resources, that is, humans have clear social constraints on the use of natural resources. And the limits are not only reflected in the livelihood technologies, but also in the associated values, religious culture and so on. The Miao people in Yunnan are mainly distributed in the deep mountains and high valleys of the brush-like mountain system in Hengduan Mountains to the west of Yuanjiang River in Wenshan and Honghe prefectures. The erosive runoff cut bare surfaces for a long time, so the limestone mountains in this area are fragmented. Farmers cut forested areas and burn the desiccated vegetation in the dry season, plant before the rainy season, and leave unfertilized stalks and grass. Therefore, this extensive agricultural livelihood can harvest about $100 \mathrm{~kg}$ of rice per mu (about 0.0667 hectares) at the first year. However, after the second and third years, soil fertility is exhausted, halving the yield. As a result, they have two kinds of cultivation modes: nonrotational and rotational systems (Du 2013, 79-83). In the former system, the cultivated land will be abandoned after one season of planting, and in the latter system, the land is fallowed once every three to five years, and more adaptable varieties such as corn, soybean, potato, buckwheat, and upland rice are inter-cropped in these fields. What's more, Miao employ fire control measures to protect forest resources and to leave enough time for the cultivated field to recover soil fertility 
Otherwise, uncertain movement, hunting and gathering also can protect local resources from running out. They constitute a sustainable and mobile way to resource development, so that the ecological environment is able to be renewed and reused. And it forms a relationship of symbiosis, coexistence, and mutual adaptation between humans and the nature. Visibly, the migration seems to be the best choice for them to adapt to the harsh habitat.

Thirdly, there are the mutual benefits among traditional livelihoods that sustain this system. It is essentially a kind of long-term dynamic equilibrium relationship of reciprocity, which not only manifests in the human and the natural ecological interactions, but also exists in terms of the relations between Miao and other ethnic groups.

On one hand, local religion also plays a significant role when natural disasters occur, or land fertility is exhausted. The Miao people believe human behaviors contradicting mountain gods, earth mothers, and earth ghosts affect one's livelihood on earth. Once the gods are offended, they will bring serious disasters such as disease and death. People believe any sin against the gods will result in gods' anger, and the gods punish them or their cultivated field, so they have to move to another place. Local religion, therefore, is also an important factor notifying Miao people's migration.

On the other hand, due to the Miao's late arrival of in Yunnan, cultivated land and other resources available to them were so extremely limited that a considerable number of them became tenant peasants and hired laborers of the Han, Yi, and Hui people, depending on these people to survive. The B Village near Kunming was gradually formed by renting cultivated land from Han landlords more than 100 years ago. There are also a symbiotic relationship between Miao people and Hui people at border areas in Yunnan, China. Old people still can recall their ancestors working as horsemen assisting Hui people to transport cloth, salt and opium. Some of them even crossed the international border into the mountains towards north of Laos and Thailand. The lack of local traders required iron tools and salt to be exchanged with foreign merchants. Hence, providing labor and frequent commerce with foreign vendors were also essential to sustain their livelihood.

Above all, through hunting and gathering, slash-and-burn cultivation and exchanges with other ethnic groups, Miao people constructed a sustainable, adaptable and diversified interactive relationship with natural resources and the multi-ethnic society. The above analysis clearly shows that the livelihood based on the cultural ecology of the highlands is the fundamental reason for the migratory dimensions of the Miao people.

\section{Current Changes of Livelihood and Highland Migration Culture of Yunnan Miao}

The current livelihood changes of the Yunnan Miao are reflected in the transformation from early shifting cultivation and tenancy to settled farming since the 1950s. During that period, the state gradually tightened restrictions on shifting cultivation of burning mountains, accompanying great changes in their traditional highland migration culture. Especially after 1983, the ownership and management system of mountain forests have gradually changed in various border areas, and the "three fixed" concepts of mountain forest rights, forestry production responsibility system, and delineation of members' selfretaining works have been implemented, which further restricted the migration for shifting cultivation (Cang 2004, 84-85). The life of settled farming, as a result, prompted the Miao people to devote themselves to irrigating their farmland and plantation. The introduction of a new agriculture based on cash crops and the use of new tools, new farming techniques, fertilizers, and pesticides have improved Miao people's living standards significantly.

For example, agriculture still dominates L village on the border of Hekou County, Honghe Prefecture, China. Statistics in 2009 showed that the average annual income of the whole village was only CNY 1,799 (USD \$276). The major reason for obvious income growth is banana cultivation. And a net income of about CNY 150,000 (USD\$23,055) was realized through banana planting in 2011. Yet, most other families did not have cultivable land to plant bananas and remained extremely poor. Consequently, wage day-laboring in the city has gradually become an important livelihood to them. In $\mathrm{C}$ village, the income of city laborers in recent years has far exceeded the incomes of those doing traditional agriculture, and it has become their most important livelihood. 
Specifically, in terms of the mobility as the means of livelihood, although large-scale moves have stagnated under the premise of the state intervention, it did not really disappear in the contemporary era, but continues part-time. Parts of Miao tribe are still keen to look for highland, forest and barren mountains, and continue their traditional livelihoods through part-time employment.

Unlike other ethnic groups, Miao peoples' work livelihoods are more extreme. For example, in C village, on the one hand, the proportion of migrant workers engaged in all kinds of industry is extremely high, accounting for 85 percent of the total population, which is significantly higher than other ethnic groups. This part of the group is mainly engaged in engineered urban construction, service industries, etc. On the other hand, since 1992, more than 10 families have gone to Yuanjiang and Xishuangbanna, and finally have moved their families to their places of employment. They are mainly engaged in renting land for planting bananas and tea. However, these families have little relationships with the local people in the employment place and the reason that they decided to go there was just because they heard there were cultivable lands available. Among them, about seven or eight households have not returned to the village, and no longer participate in important ceremonial activities in the village. Hence, the usufruct rights to their lands in the village were handed over to their relatives living in the village. Only when two or three households need to participate in major festivals in the village, weddings and funerals, and when children need to go through the formalities for studying, they occasionally came back. Quite obviously, this way of family migration can be seen as the key expression of the mobility in their traditional highland migration culture in the contemporary era. In this sense, although the livelihood foundation of the Miao people's highland migration culture has undergone fundamental changes, it still continues to a certain extent with new ways of working.

Secondly, about the limited combination between humans and nature, Miao people in Yunnan did some transformations, that is, they turned their limited development into the deep development, which has also led to widespread criticism of the destruction of the ecological environment by the Miao people's livelihood. Moreover, the impact of this change has affected many aspects of their highland migration culture, such as the changes in farming techniques, supernatural concepts, and the changes in highland migration culture.

Nowadays, many Miao people imitate the Han people to deforest wide areas to construct terraced fields. However, in central and southeast Yunnan, a considerable part of the geology is karst landform. Because "the surface soil layer is very thin and there are many underground karst caves, large areas of terraced soil can easily penetrate the gaps between the surface and underground karst caves and induce serious rocky desertification. Such ecological disasters have exacerbated the poverty of the local Miao people" (Yang 2005, 62-64). The root of the problem lies in that they directly applied the technology of land development in the plain to the alpine mountain areas, that is, from the superficial and short-term limited development to the deep and long-term development, which leads to the problem of ecological damage.

What follows is their transformation of perception of the cultivated lands. Beginning with the imposition of the household contract responsibility system in the early 1980s, the Miao peoples' traditional concept that attaches little or no importance to land use rights, and despising ownership rights, has undergone a fundamental change from a non-sedentary migratory culture. Meanwhile, almost all the land and forest resources were tenured to individual families with the reform of the forest property system. As a result, Miao people have come to establish and accept the concept about land boundaries. Accordingly, the blurring of the concept of borders by establishing mosaic parcels have naturally become important sources of disputes between villages, relatives, families, and even within families.

Meanwhile, Miao relationships to the supernatural world have also changed in this process. No matter people are afraid of the god's punishment caused by people's development or not, most of them would no longer move, and they would like to face them instead of escaping. As a result, many villages' collective sacrifice for the gods disappeared, which means that, not only the local religious atmosphere has been weakened, but their natural protection function has also been greatly reduced.

Thirdly, it is about characteristics of mutual beneficial. The relationship between the Miao people and the environment has gradually changed from an equal and mutually beneficial relationship formed by 
continuous migration, farming, hunting and gathering to an unequal and utilitarian relationship focusing on short-term benefits between the subject and the object. Even in some situations, this relationship evolves into a comprehensive and deep relationship of conquest and plunder, so it is very easy to cause damage to the environment.

For example, from 1977 to 1987 , more than 2500 square kilometers of forest were burned by the Miao people in Hoang Lien Mountain. In 1980, it was the largest, reaching 258 square kilometers. (Chen 1996, 20). At that time, the Vietnamese government even used the army and publicity to force them to stop burning and exploiting the mountain. However, this high-pressure policy has raised the Miao people's resistance. Until now, there are still some Miao people in Vietnam constantly moving to the remote mountains to establish their villages. It can be inferred that the Miao people's serious damages to the forests of the Hoang Lien Mountain Range may not only be the result of slash-and-burn livelihoods, but it may also express their resistance to government control in this way.

As we can see, the truth is that the modern states have to construct relationships on controlling populations and resources directly, which corresponds to James Scott's (1998) concept that states need to make people "legible" in order to have control over them. However, this settled cultivation mode and sedentary livelihood conflicts with the Miao people's traditional shifting cultivation, leading to the break of the balanced, interactive and mutual beneficial relationship between Miao people and the environment. As a result, the destruction to environment seems to be doomed.

\section{CONCLUSION}

In summary, we can conclude that the government's modernization projects brought about changes to the traditional highland migration culture of Miao people in Yunnan, as reflected in the transformation from the nomadic shifting cultivation lifestyle to the settled livelihood. In the process of significant improvement in the economic and living standards of contemporary Miao people, it has also triggered changes in their attitudes and relationships towards highland and mountain forests; it has brought about changes in their traditional perceptions of cultivated land rights and their boundaries; it has led to a weakening of respect for gods; and even their social relations have also deteriorated. Not only that, but this process also accelerates the integration of Miao's clans and even homogenization of their cultures. Their languages are becoming more similar, and the intermarriages between different branches are available; due to the increase of the population, the scattered layout of villages becomes more and more intensive; clothing is no longer the main identity difference among different branches, but accelerates the integration in the process of using elements of each other branches. Nevertheless, the ethnicity and the core of their highland migration culture is still inherited through nuclear and stem family's relocation and work livelihood, and continues in myths and legends, folk arts, and various ethnic groups, clan and family rituals.

\section{ACKNOWLEDGEMENTS}

Zheng Yu is a professor at the National Centre for Borderlands Ethnic Studies in Southwest China at Yunnan University, a key research base of Chinese Ministry of Education. He is mainly engaged in the study of economic ethnology and border ethnic issues. Zhang Mengyao is a PhD candidate in ethnology at School of Ethnology and Sociology of Yunnan University, and mainly is engaged in the study of economic ethnology and Miao people in Yunnan. This study was funded "Investigation and Research on Intergenerational Livelihood Changes of Miao people in Shihuaqing Village, Yunnan Province" (2020

Research Project of National Ethnic Affairs Commission of China, 2020-GMF-016) and "First Class Discipline of Yunnan University of Ethnology". 


\section{ENDNOTES}

1. Jingman is a contemptuous term for the aborigines in Jinchu area by Zhou dynasty in ancient China.

2. Namely the present west Hunan, east Guizhou, southeast Chongqing and west Hubei, China.

3. Consequently, the Hmong mercenaries fled for Thai refugee camps after Laos' liberation in 1975. Many were resettled in the United States, where some of the largest diasporic communities are located in the Upper Midwest, namely Minnesota State.

4. "zuosuo" refers to the ritual activities of praying for the members of the lineage by holding a series of witchcraft rituals to remove uncleanness. Commonly found in China's Guizhou province and Yunnan province, and Vietnam, Thailand, the United States and other places where Hmong people are gathering. See: Zheng Yu and Zeng Jing. 2013. Ceremony Types and Social Boundaries: Investigation of the Hmong People in Polong Street, Polong Township, Mengkang County, Lao Cai Province, Vietnam. Beijing: China Social Sciences Press.

5. The original source of "farmers in the forest" is the title of a compendium of papers edited by Peter Kunstadter et al in 1978, Farmers in the forest: economic development and marginal agriculture in northern Thailand.

\section{REFERENCES}

Cang, M. (2004). The History of Immigration in Yunnan Border Area. Kunming: Minzu Press Chen, Y. (1996). Hmong Culture. Hanoi: Minzu Press.

Dao, Y., \& Blake, J.L. (1993). Hmong at the Turning Point. Minneapolis: World Bridge Associates.

Du, Y. (2013). Ecological principles of slash and burn farming. Journal of Central Minzu University, 2, 79-83.

Eriksen, T.H. (1993). Ethnicity and Nationalism, Anthropological Perspectives. London: Pluto Press.

Fenton, S. (2009). Ethnicity (L. Huangqiang, Trans.). Beijing: Central Minzu University Press.

Geddes, W.R. (1976). Migrants of the Mountains: the Cultural Ecology of the Blue Miao (Hmong Njua) of Thailand. Oxford: Clarendon Press.

Geertz, C. (1973). Thick Description: Toward an Interpretive Theory of Culture. In The Interpretation of Cultures: Selected Essays (pp. 3-30). New York: Basic Books.

Golden, P.H. (2012). Cultural Sketches: Cases Studies In Anthropology (5e). Peking University Press.

Gu, W. (2011). Hierarchy of Ethnic Recognition in Miao Ethnic Group-A Case Study of "Mongolian" in Miao ethnic group. Journal of Minzu University of China (Philosophy and Social Sciences Edition), 2, 43-48.

Harrell, S. (2001). Ways of Being Ethnic in Southwest China. University of Washington Press, p. 16.

Kunstadter, P., Chapman, E.C., \& Sabhasri, S. (Eds.). (1978). Farmers in the Forest: Economic Development and Marginal Agriculture in Northern Thailand. Honolulu: University of Hawaii Press for the East-West Center.

Lebar, F. M., Hickey, G.C., Musgrave, J.K., \& Burling, R. (1964). Ethnic Groups of Mainland Southeast Asia. Human Relations Area Files Press, p. 64.

Lemoine, J. (1972). Un Village Hmong Vert Du Haut Laos. Paris: Centre National de la Recherche Scientifique.

Lebar, F.M., Hickey, G.C., \& Musgrave, J.K. (1964). Ethnic Groups of Mainland Southeast Asia. New Haven, Conn.: Human Relations Area Files Press.

Lee, G.Y. (1981). Effects of Development Measures on the Socio-economy of the White Hmong (Ph.D. dissertation). Department of Anthropology, University of Sydney.

Lin, Y. (1985). Ethnic Studies. Beijing: China Social Science Press.

Michaud, J., \& Ovesen, J. (Eds.). (2000). Turbulent Times and Enduring Peoples: Mountain Minorities in the Southeast Asian Massif. Richmond, UK: Curzon Press.

Ostrom, E. (1990). Governing the Commons: The Evolution of Institutions for Collective Action. Cambridge University Press. 
Steward, J. (1955/1985). The Concept and Method of Cultural Ecology. In Theory of Culture Change and Multilinear Evolution (pp. 1-9). Champaign, Ill.: University of Illinois Press.

Scott, J.C. (1998). Seeing Like a State: How Certain Schemes to Improve the Human Condition Have Failed. New Haven, Conn.: Yale University Press.

Scott, J.C. (2009). The Art of Not Being Governed - An Anarchist History of Upland Southeast Asia. Yale University Press.

Shi, M. (2004). Transnational Miao Studies: The Boundary between Ethnic and State. Beijing: Minzu Press.

Sun, J. (1998). Ethnic Groups and Ethnic Identity. Journal of SunYat-sen University, 2, 24-31.

Tapp, N. (2008). Southwest China and Its Framed Culture: Hmong and Other Ethnic Groups. Journal of Southwest University of Nationalities, 1, 23-31.

Wang, C., \& Beja, J.P. (1999). Wenzhou People in Paris: a Unique Model of Social Integration. Journal of Chinese Social Sciences, 6, 106-119.

$\mathrm{Wu}, \mathrm{X}$. (2006). Research on the History of the Miao Nationality, Beijing: China Literature and History Press.

Xiong, Y., \& Fenghua, Y. (2010). Entering the Hmong. Kunming: Yunnan Minzu Press.

Yang, C.N. (2002). Cultural Capital: Old Hmong Culture in Modern Times (Ed.D. Dissertation), University of Saint Thomas, Saint Paul, Minn.

Yang, T. (2005). Absence, Distortion and Recovery of Local Knowledge. Journal of Jishou University, 2, $62-84$.

Yang, T. (2007). The Value of Ecological Knowledge of Miao People in the Treatment of Rocky Desertification Disaster. Journal of Guangxi Minzu University.

Yang, Y. (2008). Perpetual Wandering: An Anthropological Study of the Migration Sense of the settled Miao People. Beijing: Social Science Archives Press.

Yin, S. (2008). The Distant Wildfire-Slash and Burn in the Perspective of Anthropology. Yunnan People's Press.

Zheng, Y., \& Jing, Z. (2013). Ceremony Types and Social Boundaries: Investigation of the Hmong People in Polong Street, Polong Township, Mengkang County, Lao Cai Province, Vietnam. Beijing: China Social Sciences Press. 